Article

\title{
Exploring Community-Oriented Approaches in Demand Side Management Projects in Europe
}

\author{
Anna Mengolini *, Flavia Gangale and Julija Vasiljevska \\ Joint Research Centre of the European Commission, Directorate C - Energy, Transport and Climate, \\ Westerduinweg 3, 1755 LE Petten, The Netherlands; flavia.gangale@ec.europa.eu (F.G.); \\ julija.vasiljevska@ec.europa.eu (J.V.) \\ * Correspondence: anna.mengolini@ec.europa.eu; Tel.: +31-244-565253
}

Academic Editor: Tan Yigitcanlar

Received: 20 October 2016; Accepted: 30 November 2016; Published: 5 December 2016

\begin{abstract}
This paper seeks to investigate if the theoretical and political trends towards a more collective dimension of energy use are reflected in the design and development of demand side management (DSM) pilot projects in Europe. Specifically, the paper analyses DSM projects in the database of the Joint Research Centre (JRC) of the European Commission to capture signs of a new attention towards the wider context in which consumers live and towards the social dimension associated with energy consumption. To this end, the paper investigates the projects' scope (in terms of project's partners, end-use sectors and targeted services) as well as the consumer engagement strategies that projects use. These elements reflect the projects' consideration for the socio-economic dimension of the community where the pilots take place and their inclination to build on community dynamics. The analysis shows that DSM projects in the EU are increasingly being designed and developed with a collegial approach to energy consumption in mind, although an integrated approach is still missing. In addition, research is still needed to link the use of this innovative approach to project results. A closer look at the developments and results of these projects can help to identify what works and what doesn't in real life experiences, thus supporting effective policy making at the EU and national level.
\end{abstract}

Keywords: demand side management; consumer; community; engagement strategies; smart grids

\section{Introduction}

The increasing penetration of distributed renewable generation and the emergence of demand side management (DSM) solutions are acting as main transformative forces in the European power sector, creating opportunities but also posing challenges to the reliability and efficiency of system operation. To address these challenges and make the power system smarter, new technological and market solutions are being tested in many countries across Europe.

Smart grid developments are expected to affect all components of the electricity system-generation, transmission, distribution and consumption-while also enabling new emerging behaviours and new social dynamics [1]. The traditional approach to power system optimization, mainly focused on the technical level, will therefore need to be complemented by approaches that include and address the social dimension of the system. The future smart grid shall indeed be considered as a sociotechnical system where the technological, economic and social layer communicate and interact [1,2]. This paper focuses on the social layer, particularly on the use of community dynamics to enhance consumer participation in the emerging energy system.

The two-way information and power flow enabled by smart metering systems can indeed allow consumers to become more aware of their energy consumption-i.e., how much energy they are using and ideally on what uses-and to make more informed decisions on their own energy supply. Moreover, 
the deployment of smart grids can enable the efficient integration of different services-electricity, water, gas, heating and cooling - in a single shared architecture, fostering conservation and a more efficient use of resources. To accelerate their deployment, however, it is argued $[3,4]$ that consumers' participation and engagement should be promoted not only at an individual level, but also taking into consideration the wider social context in which consumers live and operate.

The functioning of the smart grid will indeed rest on the interaction of a multiplicity of social players who operate as independent decision-makers driven by personal goals and attitudes as well as social interactions. Smart grids will bring forward a radical technological, environmental and economic transformation of the old system, affecting the way consumers live their lives and how they interact socially and culturally [5].

This is particularly true in the DSM domain, where consumers play a fundamental role. In this field, however, the current debate still focuses mainly on technological issues and economic incentives, mostly addressing energy demand issues with an individualistic approach to attitudes and choices [5-7]. This traditional approach concentrates primarily on individual feedback mechanisms, neglecting the complex social dimension of shared practices, goals and attitudes associated with energy consumption [7-9]. This individual-oriented approach appeals to the consumer self-enhancing values, and reflects a key concern with one's individual interests and well-being, e.g., in terms of comfort or economic savings [10].

A more recent stream of research, however, is investigating ways to activate consumer response by leveraging more on collective dynamics, suggesting a shift from an individual approach to energy management to a collegial one where consumers are seen and approached in their social context. This approach builds more on self-transcendent values and reflects a key concern with collective interests; it aims at building a sense of community and of shared values and goals [10]. Growing attention is given to strategies promoting active participation of end-users at community level, and on the role that communities can play in the transitioning energy system [11-16].

Community-based energy initiatives can indeed produce energy, reduce energy use, manage energy demand and purchase energy; they may therefore play an important role towards self-sufficiency and sustainability. These collective actions can develop solutions to meet local needs involving local people while contributing to energy security, reducing greenhouse gas emissions and keeping costs down for consumers [17]. Doci et al. [11] view these initiatives as "social niches" capable of introducing social innovations in the electricity market resulting in new forms of organizations, business models and institutions.

The collective dimension of energy use is increasingly recognised also at the European level. According to the European Commission, European consumers engage more and more in self-generation and cooperative schemes in order to better manage their energy consumption [18]. Regional and local energy initiatives are seen as facilitators of consumer participation in the energy market and in the effective governance for the Energy Union. According to [18], such initiatives should be supported, as they can provide a valuable link between decision-makers, citizens and innovators, opening new opportunities for local communities to play an active role in the energy transition.

The transition to a more participatory energy system, however, requires a shift from an approach based on individual-oriented strategies to a more comprehensive and integrated approach based on community-oriented strategies, where inclusivity and a collective sense of purpose and values are the drivers to transition [4,19-21]. A more integrated approach that leverages on collective dynamics and on the integration of different actors and sectors (such as electricity, water, gas, heating and cooling) can indeed enhance consumer participation [4].

In this context, the aim of the present paper is to investigate if the theoretical trend and socio-political acknowledgement of a more collective dimension of energy use are reflected in the design and development of DSM projects in Europe. Several studies have analysed consumer engagement strategies in smart grid projects in Europe [22-24] and in the US [25-27]. This topic is emerging also as a field of investigation in other countries including China [28], Japan [29] and 
Australia [14]. To the best of our knowledge, however, there are no comprehensive studies on the use of community-oriented approaches as a tool to increase consumer participation in demand side management projects. The analysis of recent developments in this field can help identify best practices and lessons learned from real life experiences, thus supporting effective policy making.

The paper is organized as follows: in Section 2, we present the methodological approach; in Section 3, we present the results of the analysis highlighting the findings in terms of projects' scope and engagement strategies. We also refer to some of the projects to give examples of interesting emerging practices. Finally, in Section 4, we discuss our findings and provide some policy implications of our research.

\section{Materials and Methods}

Pilot projects provide an important means to monitor the direction Europe is taking and to understand what works and what doesn't in real-life experiences. Since 2011, the JRC has been publishing an inventory of EU smart grid projects, assessing current trends and developments in the field [30-32]. Successive analyses have tried to identify those projects that specifically address consumers as key players, highlighting the main motivational factors and strategies to engage them [22] and situating the consumer in a broader social context [33].

The JRC inventory offers a valuable tool to explore the changing role of consumers in the evolving energy system: with this aim in mind, we screened the JRC database and singled out the demonstration projects with a clear focus on residential demand side management. DSM aims at matching demand with the available supply, allowing for larger integration of intermittent generation. It helps network operators manage their grids in a more flexible and efficient way and to defer investments in network reinforcement and expansion [34,35]. It also helps consumers to better manage their energy consumption by changing their behaviour and energy consumption practices. Given its broad scope and reach, different definitions of demand side management exist in the literature. For the scope of this paper, and building on recent analyses of the term [34], we included in the definition both projects that aim at shifting consumption to another point in time (demand response) and projects that aim at reducing the level of energy consumption while providing the same service and without affecting the level of comfort (energy conservation).

We focused on DSM projects as they are inherently centred on consumers and allow for the investigation of new trends in the strategies for consumer engagement. Expanding on our previous work [22,32], we looked at DSM projects in the JRC database to capture signs of new attention towards the wider context in which consumers live and towards the social dimension associated with energy consumption.

Out of 459 smart grid projects in the database, we identified 67 DSM projects. For each one of them, we collected additional information on the project's scope and on the engagement strategies used to address the individual and social dimension of energy consumption. We investigated the scope of the projects to see to what extent they take into consideration the multiplicity of actors and factors having an impact on consumers' attitudes and consumption habits. Specifically, the elements we looked into are the range of project partners, the targeted end-use sectors and the targeted services (electricity, water, gas, heating and cooling). We investigated these aspects as we believe they are key to characterizing the socio-economic scope of the projects and their inclination to build on community dynamics to impact consumers' attitudes and consumption habits. We also investigated the consumer engagement strategies used to activate consumer response and the dynamics on which they are grounded, in order to verify if a trend exists from an approach focused on consumers as individual agents to an approach that addresses consumers as socially situated individuals, part of a wider community.

The study is limited to the identification of emerging trends from DSM innovation projects in the JRC database. These projects feature multiple interventions that play out in an interactive way, and it is therefore not possible to disentangle the effects of one intervention from the contribution of 
other factors. At this stage of the research, it is therefore not possible to use the results of the projects to evaluate the effectiveness of the adopted engagement strategy. Even if we cannot yet confirm the effectiveness of initiatives characterized by a more inclusive approach, we can, however, present the evidence of an emerging interest for collective dynamics and multi-stakeholder partnerships. Further research will be devoted to investigating this topic as well as the scalability and replicability potential of community-oriented projects.

\section{Results}

\subsection{Projects' Scope}

\subsubsection{Project Partners}

Though most of the projects are still led by distribution system operators and energy companies (over $40 \%$ of them), DSM projects increasingly attract the participation of intermediary organizations, i.e., local project partners that work closely with the concerned community/territory and operate mostly at the local level. Table 1 shows the different kinds and the occurrence of local project partners, while Figure 1 presents their participation in the projects over time.

Table 1. Local partner organizations in demand side management (DSM) projects.

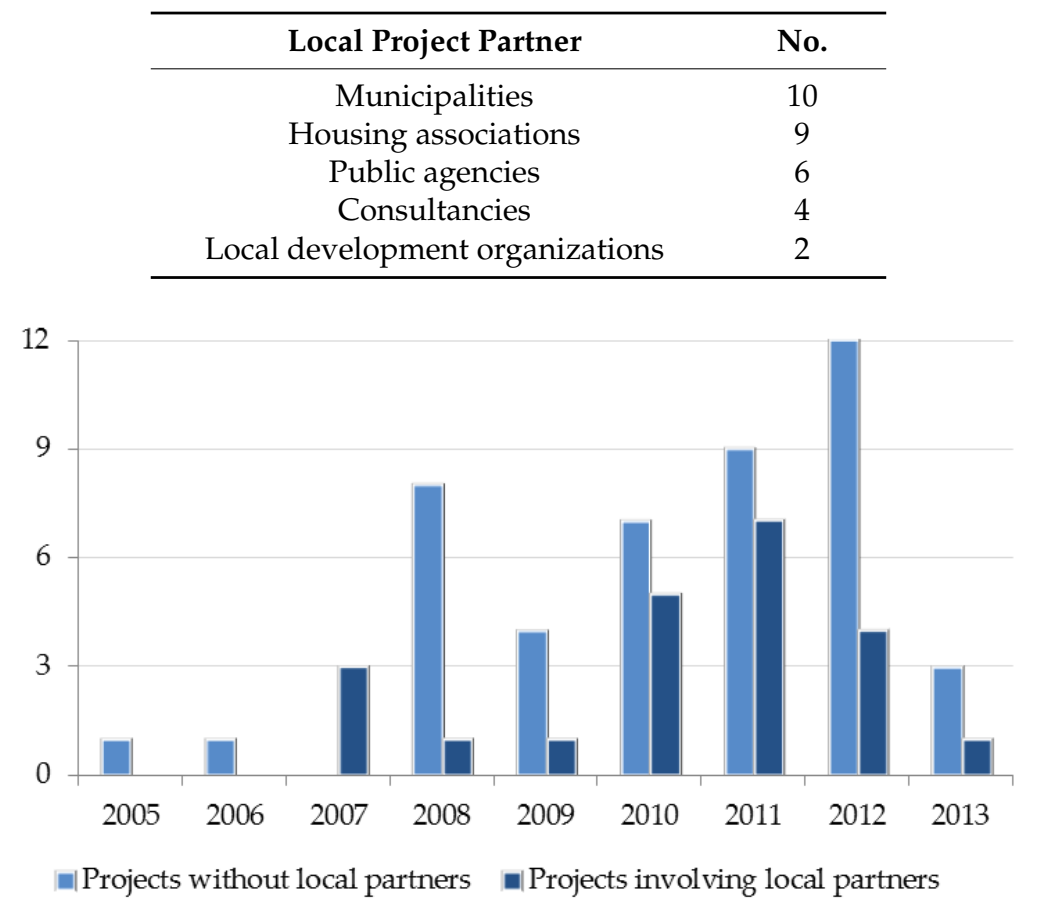

Figure 1. Evolution in the participation of local partners over time.

Municipalities are increasingly active in DSM projects. Other public sector organizations, such as public agencies for resource efficiency and housing associations, also participate in an increasing number of projects. This trend reflects the literature on the role of public and local partners to engage consumers $[3,17,36]$ and highlights the emerging interest of DSM projects in building on existing local partnerships to reach a wide range of consumers. Several studies indeed recognise the critical role of public and local partners to engage consumers, specifically to reach those that are the hardest to reach, e.g., vulnerable consumers [36]. Local partners, such as social housing providers and local community centres, benefit from a good knowledge of the local environment, and, in many cases, a high level of trust. They are, therefore, the best-suited parties to engage with local communities and reach both mainstream groups and the most vulnerable groups [36]. 


\subsubsection{End-Use Sectors}

The analysis of the projects reveals a trend towards the inclusion of different kinds of consumers within the scope of the project (Figure 2). Overall, $63 \%$ of the projects address exclusively the residential sector, while $37 \%$ of them address the residential sector in combination with the commercial, industrial or public sector. The inclusion of different sectors seems to point in the direction of addressing households within a wider context where public, commercial and industrial entities are also included. Bringing together more end-use sectors promotes the idea of a larger community effort fostering social and economic benefits for all the actors involved.

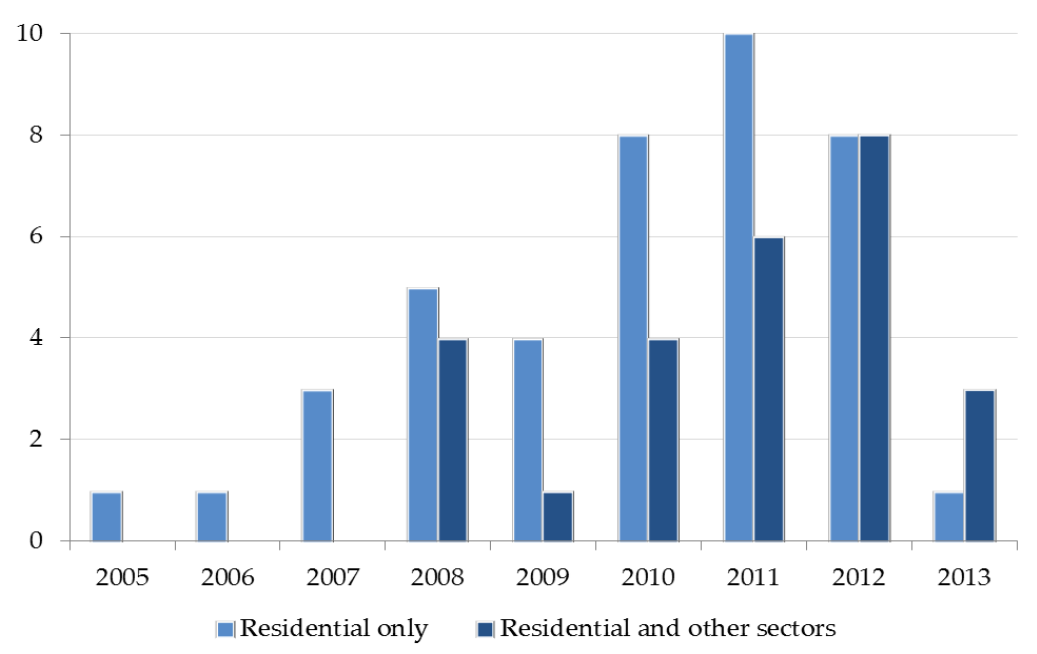

Figure 2. End-use sectors.

\subsubsection{Targeted Services}

Out of the 67 projects, 16 projects (24\%) present a cross-service approach, i.e., the inclusion of other services-water, gas, heating and cooling-in the scope of the project (Figure 3). This development is in line with the idea of integrating multiple utilities in a single shared smart grid platform. Indeed, DSM projects offer the opportunity to exploit synergies, scale and scope economies with other services. The same communication infrastructure can serve multiple meters, as well as devices providing different services [37]. At the same time, this trend is in line with the idea of a multi-stakeholder, municipally-based partnership, which is at the core of an integrated community-oriented approach. Including other services in the scope of the project can also help with maximising benefits and opportunities for consumers, thus contributing to technology acceptance and consumer engagement.

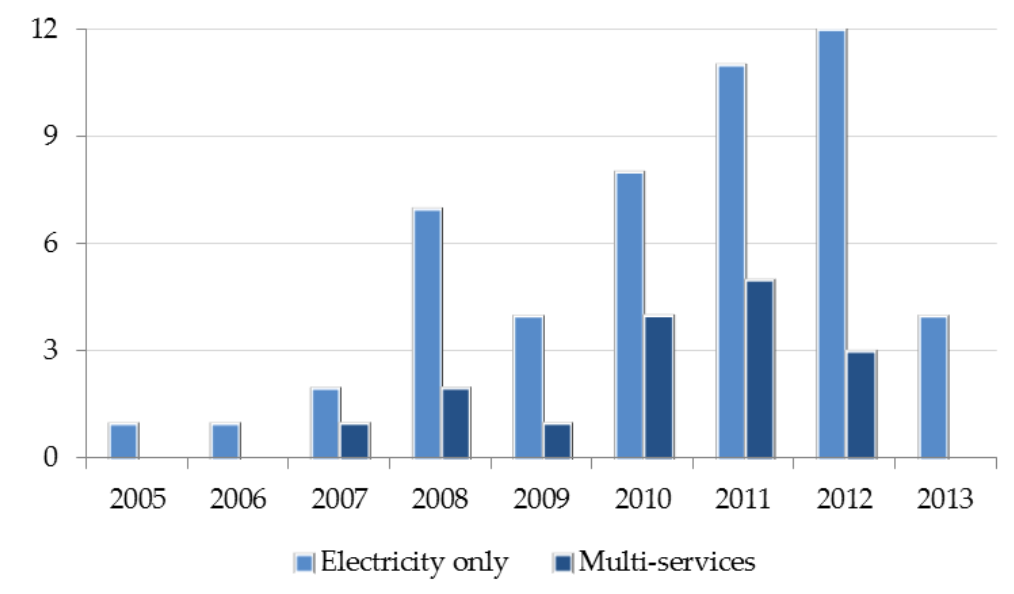

Figure 3. Evolution of multi-services projects. 


\subsection{Consumer Engagement Strategies}

To verify the argument that consumers are increasingly approached in their collective and community dimension, we also analysed the engagement strategies and tools used by all 67 projects. The analysis shows that the engagement strategies are characterized according to two main approaches: individual-oriented strategies, i.e., strategies focusing mainly on mere economic feedback mechanisms, and community-oriented strategies, i.e., strategies that adopt a more diversified and participatory approach and aim at building a sense of community and of shared goals and values. About $48 \%$ of the projects resort only to individual-centred mechanisms, while the rest of the projects mainly use a combination of the two strategies, complementing the economic feedback with the use of messages appealing to the collective interest and with the implementation of other community engagement tools. Figure 4 shows the share of projects resorting to the different approaches. In the following paragraphs, the analysis of the projects allows a deeper characterization of the two strategies and of the tools used to engage the consumers.

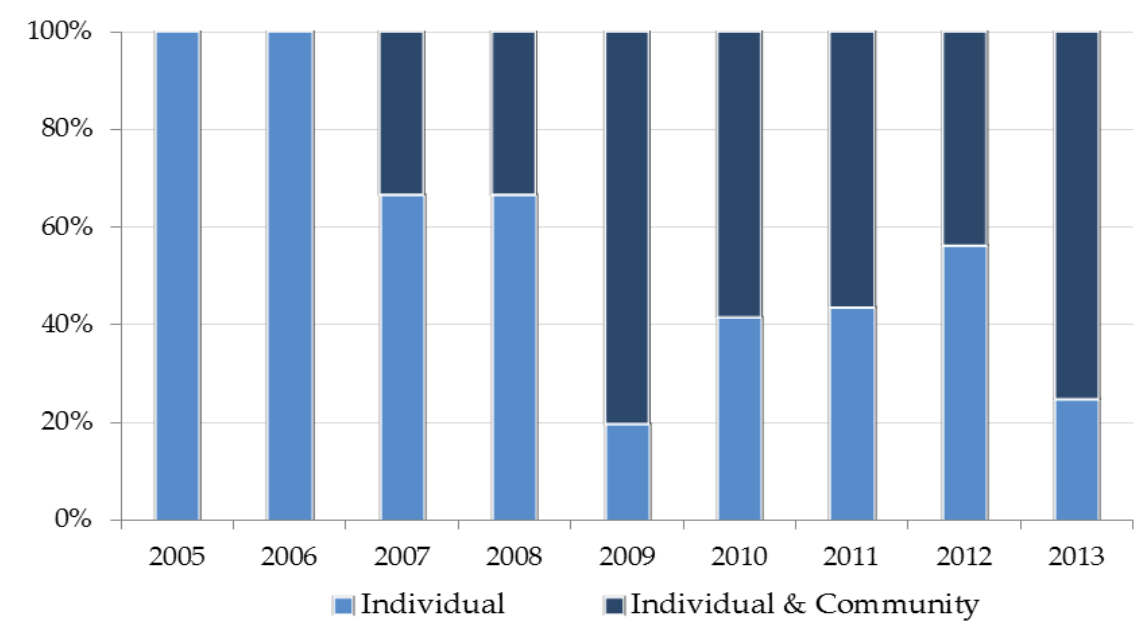

Figure 4. Engagement strategies used in the projects.

\subsubsection{Individual-Oriented Strategies}

Individual-oriented strategies appeal to the self-enhancing values of the consumer that reflect a key concern with one's individual interests, i.e., hedonic and egoistic values [10]. They mainly provide individual feedback on energy consumption, in terms of energy or monetary savings. In some projects, these strategies are coupled with engaging tools, e.g., historical comparison, expert advice/home visits, hints and tips, goals, targets and rewards (Figure 5).

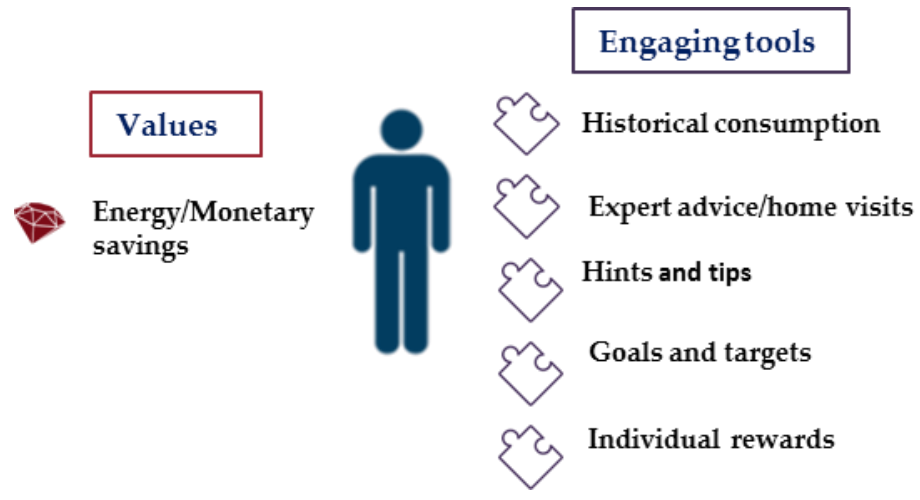

Figure 5. Individual-oriented engagement strategies. 
Only in one project (Nice Grid) does the consumer also receive information on the availability of energy from renewable energy sources (RES), a kind of information that is more typically used in community-oriented projects, as it appeals to more self-transcendent values. In this case, however, this kind of information can still be seen as appealing to the self-enhancing values, as the consumers in this project are also prosumers; the availability of RES energy, i.e., self-generated electricity, is indeed translated in economic gains. In two projects (Intrepid and 3e-Houses), social comparison strategies for individual user engagement are used. In these projects, however, the use of peer comparison seems to appeal mainly to the consumer's self-enhancing dimension ('my neighbour is saving more'), without stressing the sense of a community achievement.

\subsubsection{Community-Oriented Strategies}

Community-oriented strategies are strategies that appeal to self-transcendent values reflecting a key concern with collective interests, i.e., altruistic and biospheric values [10]. These strategies adopt a more participatory approach and aim at building a sense of community and of shared values and goals. In particular, we found that the most addressed values are environmental protection, improvement of the general welfare and being part of an innovative project. We also found that these strategies increasingly make use of social norms marketing messages and non-price interventions.

The most frequently used tools for community-oriented consumer engagement are summarized in Figure 6, while, in the rest of this paragraph, we will present some examples of projects where they were used.

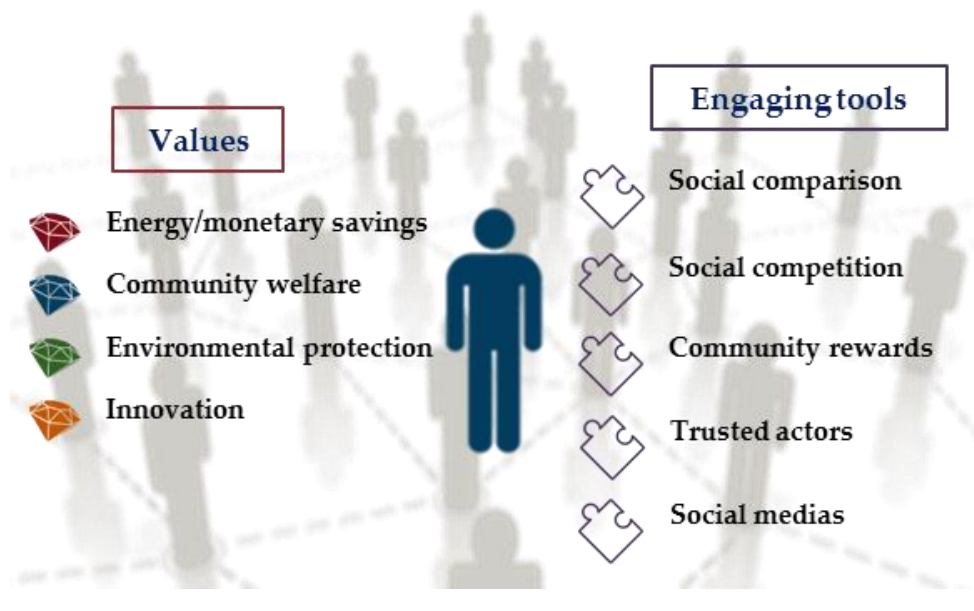

Figure 6. Community-oriented engagement strategies.

Social comparison (22/67 projects). Twenty-two projects used social comparison, a tool which compares a household's energy use to that of similar neighbours to provide a point of comparison for an individual's own behaviour. Interestingly, in order to avoid the possibility of boomerang effects-i.e., that the same message may actually serve to increase the undesirable behaviour among individuals who perform that behaviour at a rate below the norm [38]—-some projects added an injunctive message, i.e., a smiley face or a green light, indicating that the desired behaviour was approved. Indeed, adding an injunctive norm that conveys the message that energy conservation is good for the community can substantially reduce the risk of the boomerang effect [39].

The SMARTSPACES project provides the possibility to compare buildings against each other using colour-coded smileys that greet participant when they switch on their monitors. Another interesting project is the eSESH project, which also offers the possibility of comparison with other tenants in the same buildings and living in similar dwellings. Red, orange and green lights are visualized in the web portal, indicating a comparatively high, average or moderate consumption. 
Social competition/community rewards (5/67 projects). Including playful challenges and competitions enhances consumers' participation and engagement [23]. The experiences with gaming interfaces and competitive elements are promising and inspiring, both in terms of engagement and in terms of outcomes. However, a challenge of gamification is to capture the interest and attention of end users in the long run [23]. In our database, the DEHEMS Project employs a social competition strategy based on teams of households-the Energy Team Challenge, which is designed to encourage a reduction in electricity usage by leveraging on team dynamics. Electricity usage reduction is rewarded with EcoPoints that can be redeemed in exchange for "eco positive" goods and services (e.g., discount on A++ white goods for households or low energy device) that could be shared across the community [40]. This approach based on competition is meant to drive change, help engagement and provide a way of linking different stakeholders towards common societal (energy saving) and community (community reward) goals. On the same note, the Energy Demand Research Project (EDRP) applies advanced community engagement strategies where each community participating in the project can compete for a Community Project Prize (in monetary terms and of benefit to the community) for achieving a certain reduction in electricity consumption over a time period that is compared with the same time period in the previous year.

Community based social marketing strategies (14/67 projects). Social marketing is an approach that seeks, through marketing techniques, to identify the barriers that people perceive when attempting to change behaviour. Community based social marketing merges this approach with insight into the importance of social norms and community engagement in behavioural change [14,41]. The organization of community events where project participants can meet face-to-face with local residents is an effective means to reinforce community dynamics [23]. Our analysis reveals resorting to this tool, with many projects using community based events to inform and engage consumers. Community events are very often used in the recruitment phase, as, for example, in the EU-EcoGrid project; however, they are also organized in the course of the project to strengthen community dynamics after recruitment and to carry participants over to the installation and demonstration phases (e.g., green picnic and winter fairs, EDPR project).

Some projects (e.g., DEHEMS project) also employ community based social marketing to engage participants through continuing conversation and active debate [42]. An innovative form of community marketing is promoted by the DEHMES project where project users are organized in Living Labs. Living Labs are composed of groups of people who are actively involved in the creation and evaluation of technologies that they will ultimately use. In taking this approach, the project embraces the idea that changes in behaviour are often best carried out in a group or community context rather than at individual level. The presence of other people with the same interest and motivation can help to reinforce the change in behaviour (descriptive social norm: I do what others do) and to eventually turn it into an accepted and shared habit (it becomes the new accepted injunctive social norm: I do it because it is good for the community) [42]. It is, however, important to underline that the effectiveness of community engagement strategies may be also due to the specific characteristics of the community where the project is implemented (as, for example, the Island of Bornholm in the EcoGrid project and the winning community of EDPR project). These communities are strongly characterized by community-oriented consumers whose goals are related to innovation, environmental protection and community welfare (self-transcending values). Furthermore, some projects (e.g., EcoGrid) show that, in small communities, people influence each other in favour of the adoption of technologies that they see as beneficial for the community [43].

Community trusted actors ( $9 / 67$ projects). Establishing a trusted relationship with the consumer is a crucial step to overcome resistance and fully engage the consumer. Often, scepticism and wariness are reported as barriers to successful project development [22]. Recent studies on stakeholder's influence on the development of community renewable energy schemes [44] have highlighted the importance of two stakeholders: intermediary organizations acting as "trusted authorities", (see Section 3.1.1) and local champions. Local champions are actors who have significant non-material resources in term of 
individual values, skills and competencies [44]; therefore, they have the ability to easily persuade their peers and encourage behavioural change. On this note, several projects in our database report, as a best practice, the use of local champions for engaging with the community and building a trustworthy relationship. The eSESH Project reports the resort to 'champions', i.e., fellow tenants who show a strong interest in technical and energy-saving matters and who can act as multipliers by 'spreading the message' and helping neighbours in case of questions. They are highly motivated people well known by the neighbourhood [45]. Indeed, in the eSESH Project, the communication among tenants was improved to the extent that 'champions' became known experts acting as energy managers helping others and potentially learning skills that could finally be of benefit to the community. On the same note, the DEHEMS project promoted active involvement through the recruitment of community champions, i.e., proactive members of the local community, selected from the living lab population, that fulfilled both a community marketing role and a supporting role.

Social media (11/67 projects). Social media tools can also be useful for various types of campaigns, but their use requires time and dedication. An interesting example from our database is the SMARTSPACES project, where some pilots made effective use of social media tools using the cascading effect of twitter messages. These tools allowed the project to reach a wide audience, informing and engaging consumers who could pose questions and start conversations.

Table 2 lays out the main engaging tools used by community-oriented strategies, the objectives they serve to achieve, and some examples of applications from the projects in our database.

Table 2. Community-oriented strategies: tools, objectives, examples from the projects.

\begin{tabular}{lll}
\hline \multicolumn{1}{c}{ Engaging Tools } & \multicolumn{1}{c}{ Objective } & \multicolumn{1}{c}{ Examples from the Projects } \\
\hline Social comparison & $\begin{array}{l}\text { Comparing consumption level with that of a } \\
\text { similar household; indicating that the desired } \\
\text { behaviour is approved }\end{array}$ & $\begin{array}{l}\text { Red, orange, green lights; } \\
\text { colour-coded smileys }\end{array}$ \\
\hline $\begin{array}{l}\text { Social competition/ } \\
\text { community rewards }\end{array}$ & $\begin{array}{l}\text { Leveraging on team dynamics; linking different } \\
\text { stakeholder; rewarding the community }\end{array}$ & $\begin{array}{l}\text { Energy Team Challenge; EcoPoints; } \\
\text { Community Project Prize }\end{array}$ \\
\hline $\begin{array}{l}\text { Community based } \\
\text { social marketing }\end{array}$ & $\begin{array}{l}\text { Identifying barriers to adoption; reinforcing } \\
\text { community dynamics; exploiting potential for } \\
\text { behavioural change in a community context; } \\
\text { informing on the progress of the project }\end{array}$ & $\begin{array}{l}\text { Community events (e.g., green picnics, } \\
\text { winter fairs); Living Labs }\end{array}$ \\
\hline $\begin{array}{l}\text { Community } \\
\text { trusted actors }\end{array}$ & $\begin{array}{l}\text { Overcoming resistance and scepticism; building } \\
\text { trustworthy relationship; exploiting non material } \\
\text { resources of local actors }\end{array}$ & $\begin{array}{l}\text { Intermediary organizations; fellow } \\
\text { tenants; proactive local community } \\
\text { members ("local champions") }\end{array}$ \\
\hline Social media & $\begin{array}{l}\text { Reaching a wide audience; addressing questions } \\
\text { and concerns; providing information }\end{array}$ & Twitter messages \\
\hline
\end{tabular}

\section{Discussion}

This work has investigated if the current theoretical and socio-political acknowledgements of a more collective dimension of energy use are reflected in the design and development of DSM projects in Europe.

The analysis shows that DSM projects are increasingly being designed and developed with a collegial approach to energy consumption in mind, where consumers are considered in the wider socio-economic context in which they live and operate. Although the evidence of this new trend is still fragmented, there are signs of a more inclusive approach, increasingly based on community dynamics, both in the projects' scope and in the engagement strategies used therein.

The diversification of organizations, with an increasing number of local organizations participating in DSM projects, underlines the emerging interest of DSM projects in building on existing local partnerships to reach and engage a wide range of consumers. Local organizations, having good knowledge of the local environment and benefitting from a high level of trust, are indeed the best suited parties to engage with local communities. DSM projects also increasingly include different 
end-use sectors (residential, commercial, industrial and public sector) in the scope of the project, promoting the idea of a larger community effort fostering social and economic benefits for all the actors involved. Furthermore, a growing number of projects integrate multiple services (electricity, gas, water, heating and cooling) in the project proposition, thus building on the concept of a multi-stakeholder, municipally-based partnership that can maximise benefits and opportunities for consumers.

Signs of a new attention to the wider context in which consumers live and to the social dimension associated with energy consumption are also found in the increasing use of engagement strategies and tools addressing the consumer as part of a wider community. An emerging trend exists from an approach that aims at changing individual behaviours-such as the provision of consumption feedback appealing mainly to the economic self-interest-to an approach more focused on changing community's behaviours to reach goals that benefit the community at large. Many projects try to mobilise consumer's response using a more participatory approach that builds on a sense of community and of shared values and goals.

While the projects in our database resort to different combinations of partners, end-use sectors, services and consumer engagement strategies and tools to increasingly engage consumers, an integrated approach is still missing. These projects are still testing a variety of interventions that play out in an interactive way according to concrete local circumstances. It is, therefore, not yet possible to disentangle the effects of one intervention from the contribution of other factors and to link these trends to project results, thus supporting the conclusion that initiatives characterized by a more inclusive and community-oriented approach deliver better results. Further research and analysis are needed to explore this link, as well as the scalability and replicability potential of community engagement projects.

The JRC is currently working on the updating of the 2014 smart grid projects database, and new developments are already identifiable. We therefore plan to continue our analysis into the future with the aim of yielding data and insights that can help shape future policy making under the European Commission New Deal for Energy Consumers [18]. A closer look at the developments and results of DSM projects that make use of the described innovative approaches can be valuable to identify what works and what doesn't in real life experiences and therefore support effective policy making.

Author Contributions: The presented research was conjointly designed and carried out by Anna Mengolini, Flavia Gangale and Julija Vasiljevska. The data analysis and discussion were realized conjointly. All authors contributed equally in the writing of this paper. All authors have read and approved the final manuscript.

Conflicts of Interest: The authors declare no conflict of interest.

\section{References}

1. Bompard, E.; Han, B.; Masera, M.; Pons, E. Smart Grid as Multi-layer Interacting System for Complex Decision Making. In Networks of Networks: The Last Frontier; D’Agostino, G., Scala, A., Eds.; Springer: Berlin, Germany, 2014.

2. Bayram, I.S.; Ustun, T.S. A survey on behind the meter energy management systems in smart grid. Renew. Sustain. Energy Rev. 2016, in press. [CrossRef]

3. Goedkoop, F.; Devine-Wright, P. Partnership or placation? The role of trust and justice in the shared ownership of renewable energy projects. Energy Res. Soc. Sci. 2016, 17, 135-146. [CrossRef]

4. Koirala, B.P.; Koliou, E.; Friege, J.; Hakvoort, R.A.; Herder, P.M. Energetic communities for community energy: A review of key issues and trends shaping integrated community energy systems. Renew. Sustain. Energy Rev. 2016, 56, 722-744. [CrossRef]

5. Verbong, G.P.J.; Beemsterboer, S.; Sengers, F. Smart grids or smart users? Involving users in developing a low carbon electricity economy. Energy Policy 2013, 52, 117-125. [CrossRef]

6. Geelen, D.; Reinders, A.; Keyson, D. Empowering the end-user in smart grids: Recommendations for the design of products and services. Energy Policy 2013, 61, 151-161. [CrossRef]

7. Goulden, M.; Bedwell, B.; Rennick-Egglestone, S.; Rodden, T. Alexa Spence Smart grids, smart users? The role of the user in demand side management. Energy Res. Soc. Sci. 2014, 2, 21-29. [CrossRef] 
8. Wolsink, M. The research agenda on social acceptance of distributed generation in smart grids: Renewable as common pool resources. Renew. Sustain. Energy Rev. 2012, 16, 822-835. [CrossRef]

9. Shove, E. Beyond the ABC: Climate Change Policy and Theories of Social Change. Environ. Plan. A 2010, 42, 1273-1285. [CrossRef]

10. Steg, L.; Bolderdijk, J.W.; Keizer, K.; Perlaviciute, G. An Integrated Framework for Encouraging Pro-environmental Behaviour: The role of values, situational factors and goals. J. Environ. Psychol. 2014, 38, 104-115. [CrossRef]

11. Dóci, G.; Vasileiadou, E.; Petersen, A.C. Exploring the transition potential of renewable energy communities. Futures 2015, 66, 85-95. [CrossRef]

12. Van der Schoor, T.; Scholtens, B. Power to the people: Local community initiatives and the transition to sustainable energy. Renew. Sustain. Energy Rev. 2015, 43, 666-675. [CrossRef]

13. Alvial-Palavicino, C.; Garrido-Echeverría, N.; Jiménez-Estévez, G.; Reyes, L.; Palma-Behnke, R. A methodology for community engagement in the introduction of renewable based smart microgrid. Energy Sustain. Dev. 2011, 15, 314-323. [CrossRef]

14. Anda, M.; Temmen, J. Smart metering for residential energy efficiency: The use of community based social marketing for behavioural change and smart grid introduction. Renew. Energy 2014, 67, 119-127. [CrossRef]

15. Burchell, K.; Rettie, R.; Roberts, T.C. Householder engagement with energy consumption feedback: The role of community action and communications. Energy Policy 2016, 88, 178-186. [CrossRef]

16. Olson-Hazboun, S.K.; Krannich, R.S.; Robertson, P.G. Public views on renewable energy in the Rocky Mountain region of the United States: Distinct attitudes, exposure, and other key predictors of wind energy. Energy Res. Soc. Sci. 2016, 21, 167-179. [CrossRef]

17. Department of Energy \& Climate Change. Community Energy Strategy: Full Report. Available online: https://www.gov.uk/government/uploads/system/uploads/attachment_data/file/275163/ 20140126Community_Energy_Strategy.pdf (accessed on 24 November 2016).

18. European Commission. COM(2015) 339 Final, Delivering a New Deal for Energy Consumers; European Commission: Brussels, Belgium, 2015.

19. Barr, S.; Devine-Wright, P. Resilient communities: Sustainabilities in transition. Local Environ. 2012, 17, 525-532. [CrossRef]

20. Rae, C.; Bradley, F. Energy autonomy in sustainable communities-A review of key issues. Renew. Sustain. Energy Rev. 2012, 16, 6497-6506. [CrossRef]

21. Wirth, S. Communities matter: Institutional preconditions for community renewable energy. Energy Policy 2014, 70, 236-246. [CrossRef]

22. Gangale, F.; Mengolini, A.; Onyeji, I. Consumer engagement: An insight from smart grid projects in Europe. Energy Policy 2013, 60, 621-628. [CrossRef]

23. S3C Consortium. Report on Case Analyses, Success Factors and Best Practices. Available online: https: / / www.zenodo.org/record/31492\#.WEEpH31EOVs (accessed on 24 November 2016).

24. Kessels, K.; Kraan, C.; Karg, L.; Maggiore, S.; Valkering, P.; Laes, E. Fostering Residential Demand Response through Dynamic Pricing Schemes: A Behavioural Review of Smart Grid Pilots in Europe. Sustainability 2016, 8, 929. [CrossRef]

25. Smart Grid Consumer Collaborative. Excellence in Consumer Engagement. Available online: http://smartgridcc.org/wp-content/uploads/2011/10/SGCC-Excellence-in-Consumer-Engagement.pdf. pdf (accessed on 24 November 2016).

26. U.S. Department of Energy. Voices of Experience: Insights on Smart Grid Customer Engagement. Available online: https://www.smartgrid.gov/featured_initiatives/voice_experience_insights_smart_grid_customer_ engagement.html (accessed on 24 November 2016).

27. Hewitt, D.; Pratt, J.; Smith, G. Recommendations for Community-Based Energy Program Strategies. Available online: https://www.veic.org/documents/default-source/resources/reports/recommendationsfor-community-based-energy-program-strategies.pdf (accessed on 24 November 2016).

28. Jiang, P.; Chen, Y.; Xu, B.; Dong, W.; Kennedy, E. Building low carbon communities in China: The role of individual's behaviour change and engagement. Energy Policy 2013, 60, 611-620. [CrossRef]

29. Mah, D.N.; Wu, Y.-Y.; Ip, J.C.; Hillsc, P.R. The role of the state in sustainable energy transitions: A case study of large smart grid demonstration projects in Japan. Energy Policy 2013, 63, 726-737. [CrossRef] 
30. Giordano, V.; Meletiou, A.; Covrig, C.F.; Mengolini, A.; Ardelean, M.; Fulli, G. Smart Grid Projects in Europe: Lessons Learned and Current Developments. Available online: http://ses.jrc.ec.europa.eu/ publications/reports/smart-grid-projects-europe-lessons-learned-and-current-developments (accessed on 24 November 2016).

31. Giordano, V.; Meletiou, A.; Covrig, C.F.; Mengolini, A.; Ardelean, M.; Fulli, G. Smart Grid Projects in Europe: Lessons Learned and Current Developments (2012 update). Available online: http://esna.org/2013/july/ article15/index.html (accessed on 24 November 2016).

32. Smart Grid Projects Outlook 2014. Available online: http://ses.jrc.ec.europa.eu/smart-grids-observatory (accessed on 24 November 2016).

33. Mengolini, A.; Vasiljevska, J. The Social Dimension of Smart Grids: Consumer, Community, Society. Available online: https:/ /ec.europa.eu/jrc/en/publication/eur-scientific-and-technical-research-reports / social-dimension-smart-grids-consumer-community-society (accessed on 24 November 2016).

34. Warren, P. A review of demand-side management policy in the UK. Renew. Sustain. Energy Rev. 2014, 29, 941-951. [CrossRef]

35. Zhang, S.; Jiao, Y.; Chen, W. Demand-side management (DSM) in the context of China's on-going power sector reform. Energy Policy 2017, 100, 1-8. [CrossRef]

36. Low Carbon Networks Fund submission from UK Power Networks. Vulnerable Customer and Energy Efficiency. Available online: https://www.ofgem.gov.uk/sites/default/files/docs/2013/11/ lcnf_submission_uk_power_networks_-_vulnerable_customers_and_energy_efficiency_0.pdf (accessed on 24 November 2016).

37. Cervigni, G.; Larouche, P. Regulating Smart Metering in Europe: Technological, Economic and Legal Challenges; Centre on Regulation in Europe (CERRE): Brussels, Belgium, 2014.

38. Schultz, P.W.; Nolan, J.M.; Cialdini, R.B.; Goldstein, N.J.; Griskevicius, V. The Constructive, Destructive, and Reconstructive Power of Social Norms. Psychol. Sci. 2007, 18, 429-434. [CrossRef] [PubMed]

39. Allcott, H. Social norms and energy conservation. J. Public Econ. 2011, 95, 1082-1095. [CrossRef]

40. DEHMES Project. Report Detailing Model for a Pilot for Emission Trading. Available online: http://cordis. europa.eu/docs/projects/cnect/9/224609/080/deliverables/001-D86DehemsDeliverable.pdf (accessed on 24 November 2016).

41. Jackson, T. Motivating Sustainable Consumption: A Review of Evidence on Consumer Behaviour and Behavioural Change. Available online: http:/ /www.sustainablelifestyles.ac.uk/sites/default/files / motivating_sc_final.pdf (accessed on 24 November 2016).

42. DEHMES Project. Report for Citizens. Available online: http://cordis.europa.eu/docs/projects/cnect/9/ 224609/080/deliverables/001-D87DehemsDeliverable.pdf (accessed on 24 November 2016).

43. EcoGrid EU Project. EcoGrid EU Replication Roadmap. Available online: http://www.eu-ecogrid.net/ images/Documents/D7.4_160127_final.pdf (accessed on 24 November 2016).

44. Ruggiero, S.; Onkila, T.; Kuittinen, V. Realizing the social acceptance of community renewable energy: A process-outcome analysis of stakeholder influence. Energy Res. Soc. Sci. 2014, 4, 53-63. [CrossRef]

45. eSESH Project. Final Report. Available online: http://esesh.eu/fileadmin/eSESH/download/documents/ eSESH_Final_Report.pdf (accessed on 24 November 2016).

(C) 2016 by the authors; licensee MDPI, Basel, Switzerland. This article is an open access article distributed under the terms and conditions of the Creative Commons Attribution (CC-BY) license (http://creativecommons.org/licenses/by/4.0/). 